\title{
La empresa pública local: Aspectos jurídico-formales de la gestión municipal de intereses económicos mediante sociedad anónima
}

\author{
Vitelio M. Tena Piazuelo \\ Profesor de Derecho Administrativo \\ Universidad de Zaragoza
}

\begin{abstract}
SUMARIO: PLANTEAMIENTO. I. MARCO LEGAL GENERAL DE LA ACTUACION ECONOMICA DE LOS AYUNTAMIENTOS. II. BREVE REFERENCIA A LOS MODOS DE GESTION DE LAS ACTIVIDADES DE INTERES MUNICIPAL. III. ASPECTOS JURIDICO-FORMALES: A) Procedimiento administrativo general para la iniciación de actividades económicas. B) Procedimiento jurídico-mercantil de constitución de una sociedad anónima pública. IV. ALGUNAS CUESTIONES DE INTERES EN TORNO AL FUNCIONAMIENTO DE LA SOCIEDAD: A) Denominación. B) Objeto social. C) Duración. D) Capital social. E) Organo de administración. F) Presupuestos y fiscalización. V. A MODO DE CONCLUSION.
\end{abstract}

\section{PLANTEAMIENTO}

La actividad económica local, particularmente la de los Municipios, ha venido siendo objeto de constante atención por la doctrina. Buena muestra de ello es el muy numeroso catálogo de trabajos que han visto la luz en ésta y en otras Revistas especializadas, así como el no menos destacable conjunto de monografías que ha aparecido en los últimos cuarenta años. Sería incluso pretencioso, por su gran circulación y aceptación, intentar ahora una simple enumeración de obras que se encuentran ya entre los clásicos en la materia. En cualquier caso, no es éste el objeto de las líneas que siguen. Tan sólo responden a la constatación de un fenómeno, sin duda singular, que se ha producido en el plano legislativo en los últimos años.

Se trata de la convergencia en un momento histórico determinado de reformas legales, con un grado de profundidad variable, en los dos extremos que confluyen en la realidad que identificamos con los términos «empresa local".

En efecto, mediados los años ochenta se ha llevado a cabo la gran operación consistente en adecuar el Ordenamiento jurídico local al nuevo 
marco institucional definido por la Constitución de 1978 (en adelante, $\mathrm{CE}$ ). Proceso, como es sabido, todavía inconcluso en sus últimos pasos -de carácter reglamentario-, pero decididamente asentado. Casi simultáneamente, si no por idénticas razones sí por causas indesligables de la anterior, se ha acometido, a finales de los años ochenta, la reforna de la legislación mercantil reguladora de las sociedades de capital.

Estos acontecimientos suponen la redefinición casi completa, no sólo en términos de legalidad formal, del Ordenamiento jurídico aplicable, en general, a la actuación de las Entidades locales y de modo destacado a esa actuación consistente en la gestión de intereses económicos. Por ello abordamos aquí, con una vocación eminentemente práctica no exenta de cierto grado de sistematicidad, los aspectos jurídico-formales del caso más notable de esa gestión, cual es la que se traduce en la utilización por el Municipio de la forma de sociedad anónima 1.

La utilización racional y efectiva por parte de las autoridades locales de las posibilidades que les ofrece en este punto el Ordenamiento, exige un esfuerzo, permanentemente renovado, de fundamentación teórica global, pero también demanda el esclarecimiento de las vías por las cuales pueda llegar a ser operativa. En este campo pretendemos movernos al explicar aquí las reglas del juego que han de ser aplicadas. Una última advertencia es preciso realizar, puesto que en aras de una mayor claridad de la exposición vamos a obviar por completo los problemas referidos a la hipótesis marcadamente singular, de ejercicio en régimen de monopolio de las actividades o servicios que, con base en el art. 128, pfo. 2, segundo inciso CE, están reservados a las Entidades locales por el art. 86, pfo. 3 de la Ley 7/1985, de 2 de abril, Reguladora de las Bases del Régimen Local (en adelante, LRBRL) ${ }^{2}$.

\footnotetext{
${ }^{1}$ Un tratamiento más ambicioso, con pretensiones de generalidad, exigiría abordar también, y por separado en aquellas características específicas que presenta el fenómeno, igualmente tradicional, de la provincialización; es decir, la constitución de empresas públicas para la gestión de intereses económicos de ámbito provincial, tarea que no asumimos directamente aquí, sin perjuicio de que muchas de las referencias y consideraciones que recogemos puedan tener aplicación al mismo por lo que suponen de base teórica y legal común en la materia tanto para Municipios como para Provincias. Sobre este asunto, vid. el reciente trabajo de Javier SALAS HERNANDEZ, «La provincialización de servicios (iniciativa pública en la actividad económica y reserva al sector público en el ámbito provincial)", en Rafael GOMEZ-FERRER MORANT (Dir.), La provincia en el sistema constitucional, Diputació de Barcelona-Civitas, Madrid, 1991, pp. 119-216, en tono crítico con la legislación, heredera a su entender de la ambigüedad y el confusionismo que preside desde siempre este campo.
}

${ }^{2}$ La interpretación de este artículo ha suscitado incluso alguna polémica doctrinal en la que no pretendemos terciar. Sobre el mismo, entre las aportaciones más recientes, vid. las siguientes: GOMEZ-FERRER MORANT, «Reserva al sector público de recursos o servicios esenciales", en Estudios sobre la Constitución Española. Homenaje al Profesor 


\section{MARCO LEGAL GENERAL DE LA ACTUACION ECONOMICA DE LOS AYUNTAMIENTOS}

$\mathrm{Al}$ abordar, desde una perspectiva jurídica, la empresa pública local debe partirse de la constatación del fenómeno general en el que organizativamente se inscribe. Se trata del soporte institucional que ofrece la «autonomía local», reconocida y garantizada por los arts. 137 y 140 de la Constitución Española de 1978, tal como ha sido definida por el Tribunal Constitucional desde sus primeras Sentencias 3, en cuanto derecho a participar a través de órganos propios en el gobierno y administración de cuantos asuntos atañen al interés local. Esta definición de la autonomía local aporta negativamente un dato no por conocido menos importante: las Corporaciones locales no gozan de potestad legislativa, por lo que la normación legal de aquellos asuntos que les atañen tiene origen externo a las mismas y puede ser doble: estatal y autonómico ${ }^{4}$.

No es éste lugar apropiado para analizar la articulación del Estado Autonómico por lo que hace al régimen local ni tampoco el tema de las fuentes del Derecho en este campo. Baste simplemente dejar constancia

Eduardo García de Enterría, vol. V, Civitas, Madrid, 1991, pp. 3803-3837; Rafael ENTRENA CUESTA, "El modelo económico de la Constitución Española de 1978», en el vol. col. La Empresa en la Constitución Española, Fomento del Trabajo Nacional-Editorial Aranzadi, Pamplona, 1989, pp. 32 y 33; Gaspar ARIÑO ORTIZ, "Propiedad, libertad y empresa», Ibid., pp. 132-135; Sebastián MARTIN-RETORTILLO, Derecho Administrativo Económico I, La Ley, Madrid, 1988, pp. 251-258, 294-297 y 316-320; Luis ORTEGA ALVAREZ, El régimen constitucional de las competencias locales, INAP, Madrid, 1988, pp. 76-92; ARIÑO ORTIZ, Comentario al art. 128, en ALZAGA (Dir.), Comentarios a las Leyes Politicas. La Constitución Española de 1978, Edersa, Madrid, 1985, pp. 23-56.

3 Es sobradamente conocida la Sentencia 32/1981, de 28 de julio, que alude a la misma en los siguientes términos: "...la garantía institucional no asegura un contenido concreto o un ámbito competencial determinado y fijado de una vez por todas, sino la preservación de una institución en términos recognoscibles para la imagen que de la misma tiene la conciencia social en cada tiempo y lugar. Dicha garantía es desconocida cuando la institución es limitada de tal modo que se le priva prácticamente de sus posibilidades de existencia real como institución para convertirse en un simple nombre..." (Fundamento Jurídico 3).

4 El concepto, origen, configuración y consecuencias de la autonomía local ha sido profusamente abordado por la doctrina. Vid. Francisco SOSA WAGNER, "La Autonomía local», en Homenaje al Profesor García de Enterría..., op. cit., vol. IV, pp. 3185-3225; Antonio FANLO LORAS, Fundamentos constitucionales de la autonomía local (El control sobre las Corporaciones locales: el funcionamiento del modelo constitucional de autonomía local), Centro de Estudios Constitucionales, Madrid, 1990; Miguel SANCHEZ MORON, La autonomía local. Antecedentes históricos y significado constitucional, Civitas, Madrid, 1990; Luis MORELL OCAÑA, El régimen local español, vol. I, Civitas, Madrid, 1988, pp. 37-58; Luciano PAREJO ALFONSO, Derecho básico de la Administración local, Ariel, Barcelona, 1988, pp. 91-173; en ellos, abundantes referencias, que abarcan hasta los conocidos trabajos pioneros de PAREJO ALFONSO y EMBID IRUJO. 
de esta dualidad («carácter bifronte» se le ha llamado), en los términos en que el art. 149, pfo. 1, $18^{\mathrm{a}} \mathrm{CE}$ atribuye al Estado (a los órganos centrales del Estado) la competencia para dictar la legislación básica del régimen jurídico de la Administración local, competencia estatal que permite una legislación autonómica sobre esta materia en desarrollo de las previsiones de aquélla. Pero sólo es tal en las Comunidades Autónomas constituidas al amparo de la "vía rápida" del art. $151 \mathrm{CE}$. Así, por lo que se refiere, v.gr., a Aragón, Comunidad Autónoma constituida por la vía del art. 143, no ha podido asumir esa competencia de la que hablábamos, sino las que le permite el art. 148 , pfo. $1,2^{\text {a }}$, esto es, «Las alteraciones de los términos municipales comprendidos en su territorio $\mathrm{y}$, en general, las funciones que correspondan a la Administración del Estado sobre las Corporaciones locales y cuya transferencia autorice la legislación sobre Régimen local», texto que fue reproducido casi literalmente por el art. 35, pfo. 1, $2^{\text {a }}$ de la Ley Orgánica 8/1982, de 10 de agosto, que aprobó el Estatuto de Autonomía de Aragón. Y a consecuencia de ello la Comunidad Autónoma de Aragón ha adoptado legislación propia que, sin embargo, se limita a aspectos muy concretos, que no afectan directamente al asunto que nos ocupa, sino a cuestiones organizativas de tipo supramunicipal (Mancomunidades de Municipios, coordinación de Policías Locales, relaciones con Diputaciones Provinciales, etc.) 5 . Fijado esto, habremos de centrar, pues, nuestra atención en la legislación exclusivamente estatal.

Ahora bien, el dato negativo que, en cuanto a la posibilidad de normación con fuerza y valor de Ley, nos aportaba la definición de la autonomía local no debe hacer olvidar que el contenido mínimamente preciso de esa autonomía consiste, de acuerdo con la doctrina reiteradamente sentada por el Tribunal Constitucional, en que los órganos locales estén dotados de aquellas potestades administrativas que posibilitan una actuación autónoma de las Entidades locales. Potestades que les atribuye, para ejercerlas dentro de la esfera (material y territorial) de sus competencias, el art. 4 LRBRL: potestades reglamentaria, de autoorganización, tributaria, planificadora, expropiatoria, etc. ${ }^{6}$. Es ahí donde

\footnotetext{
5 Una visión más exacta, con carácter crítico y referida al ejemplo citado, FANLO LORAS, «La Administración local», en EMBID (Dir.), Derecho público aragonés. Estudios sobre el Derecho de la Comunidad Autónoma de Aragón, Justicia de Aragón-Ibercaja, Zaragoza, 1990, pp. 281-296. Para una explicación general del sistema de fuentes del Derecho local, MORELL OCAÑA, op. cit., pp. 135-168 y GOMEZ-FERRER, "Legislación básica en materia de régimen local: relación con las leyes de las Comunidades Autónomasn, en La Provincia..., op. cit., pp. 45-73.

6 Sobre el significado, particular y de conjunto, de estas potestades, vid. FANLO LORAS, "Las prerrogativas locales», en MUÑOZ MACHADO (Dir.), Tratado de Derecho Municipal, vol. I, Civitas, Madrid, 1988, pp. 493-530.
} 
debemos engarzar la posibilidad -legalmente reconocida como veremos- que tienen las Entidades locales de constituir empresas bajo distintas formas jurídicas.

No es preciso recordar ahora en detalle cómo los Municipios han acometido tradicionalmente actividades de tipo industrial o comercial para subvenir a necesidades muy concretas de los vecinos, de forma progresivamente creciente, pasando a menudo a ser prestadas directamente como servicios municipalizados, incluso monopolísticamente por exclusión de la iniciativa privada en un campo o sector determinado 7 . Esta realidad histórica encuentra hoy un perfecto encuadre constitucional y legal.

Constitucionalmente, deben entenderse referidos también los Municipios en las que podemos denominar declaraciones constitucionales de principios en orden al establecimiento del Estado social (en el mismo Preámbulo y en los arts. 1 y 9, pfo. 2) y en las concreciones de los mismas en el ámbito económico (contenidas en el Capítulo Tercero del Título Primero como "principios rectores de la política social y económica» y en el Título VII relativo a "Economía y Hacienda»). No nos referimos en absoluto al valor normativo de estos preceptos, cuestión suficientemente tratada por la doctrina constitucional y administrativa, sino que aludimos tan sólo con esta terminología a la potencialidad que encierran en cuanto máximas de las que parte el constituyente al prefigurar de manera muy concreta el tipo de Estado, con contenidos determinados, que diseña.

Las Entidades locales, los Municipios en particular, son igualmente destinatarias de aquellas encomiendas o mandatos que realiza el texto constitucional con una referencia genérica a los «poderes públicos». Es innegable que todas las piezas de la estructura político-administrativa participan de las exigencias que impone la formulación del Estado social, aunque tengan oportunamente reconocida una esfera de autonomía para la gestión de sus respectivos intereses. Tanto más cuanto que la propia legislación local se hace eco de este espíritu. Así, el art. 25 LRBRL declara que «El Municipio, para la gestión de sus in-

\footnotetext{
${ }^{7}$ Abundantes referencias históricas se encuentran en la bibliografía existente desde principios de siglo. Son clásicos los trabajos de José Luis VILLAR PALASI, "La actividad industrial del Estado en el Derecho administrativo" Revista de Administración Pública núm. 3, 1950, pp. 53-129, Manuel Francisco CLAVERO AREVALO, Municipalización y provincialización de servicios en la Ley de Régimen Local, IEAL, Madrid, 1952 y Eduardo GARCIA DE ENTERRIA, "La actividad industrial y mercantil de los municipios», Revista de Administración Pública núm. 17, 1955, pp. 87-138, y a partir de entonces se han sucedido otros muchos. Más recientemente, una síntesis muy ilustrativa en S. MARTIN-RETORTILLO, op. cit., pp. 309-320 y 225-228.
} 
tereses y en el ámbito de sus competencias, puede promover toda clase de actividades y prestar cuantos servicios públicos contribuyan a satisfacer las necesidades y aspiraciones de la comunidad vecinal». En el mismo sentido, ya más concretamente, el art. 96 del Real Decreto Legislativo 781/1986, de 18 de abril, por el que se aprueba el Texto Refundido de las Disposiciones vigentes en materia de Régimen Local (en adelante, TRRL) le confiere una amplia facultad de iniciativa para el ejercicio de actividades económicas, que podrá abarcar «cualquier tipo de actividad" que sea considerada de utilidad pública y se preste en beneficio de sus habitantes, dentro de los límites del término municipal y en régimen de libre competencia empresarial. Esta concreción al ámbito local del reconocimiento de la iniciativa pública económica que efectúa el art. 128, pfo. 2 CE, exige, según el art. 86, pfo. 1 LRBRL, expediente acreditativo de la conveniencia y oportunidad de la medida, con los requisitos especificados en los arts. 96 y ss. TRRL. Se deja ver aquí bien a las claras la importancia significativa que se atribuye a los Municipios como unidades inmediatas de dinamización y estímulo del entramado económico en el nivel más próximo al ciudadano.

\section{BREVE REFERENCIA A LOS MODOS DE GESTION DE LAS ACTIVIDADES DE INTERES MUNICIPAL}

El limitado poder normativo local al que aludíamos se ve compensado pues, con un amplio reconocimiento de la capacidad de las Entidades locales para incidir en la conformación social de acuerdo con los mandatos de la Constitución. La legislación reguladora del Régimen local permite el desarrollo de esas actividades a través de medios notablemente variados. El esquema que se establece parte, como es sabido, de la distinción básica según que las actividades o servicios de interés y competencia municipal se lleven a cabo a través de las que se denominan gestión directa o gestión indirecta, siendo un principio fundamental en la materia el de la indiferencia relativa del medio, esto es, que la Corporación puede decidir libremente realizar una actividad por cualesquiera de los medios lícitos que se le reconocen, con la sola salvedad de que se prohíben los modos indirectos de gestión para aquellas actividades o servicios que impliquen ejercicio de autoridad. Así se pronuncian los arts. 85, pfo. 2 LRBRL y 95, pfo. 1 TRRL 8 .

La clasificación de las formas de gestión que acoge la legislación vigente incluye, por lo que ahora nos interesa, la gestión por sociedad

\footnotetext{
8 Sobre el conjunto de estas técnicas, vid. Juan Francisco MESTRE DELGAD0, en Tratado..., op. cit., vol. II, pp. 1223-1300. Para una referencia histórica, F. ALBI, Tratado de los modos de gestión de las Corporaciones locales, Aguilar, Madrid 1960.
} 
anónima, distinguiendo, según el nivel de la participación pública en la misma, dos supuestos.

En primer lugar, entre las modalidades de la que llama gestión directa, se encuentra la gestión por "Sociedad mercantil cuyo capital social pertenezca íntegramente a la Entidad local» (art. 85, pfo. 3 c) LRBRL). Es una de las formas, la más pura, de constitución de un sector público local, en este caso mediante el recurso a sociedades de capital en las que únicamente participa la Corporación, con las destacables consecuencias que ello acarrea en punto al control y funcionamiento de la empresa, que se encuentra por completo en manos públicas, sin intervención, ni siquiera minoritaria, de capital procedente de manos privadas. El art. 103 TRRL precisa que la forma de estas sociedades deberá ser alguna de las de responsabilidad limitada, esto es, sociedad anónima o sociedad de responsabilidad limitada, a cuya regulación legal y a la escritura fundacional remite su régimen completo, con la única exigencia reiterada de que el capital de la sociedad sea aportado íntegramente por la Entidad local. Se tipifica asimismo un motivo de obligatoria disolución de la sociedad, que procederá cuando las pérdidas sean superiores a la mitad del capital social.

En segundo lugar, entre las calificadas como de gestión indirecta, la realizada mediante "Sociedad mercantil y cooperativas legalmente constituídas cuyo capital social sólo parcialmente pertenezca a la Entidad local» (art. 85, pfo. 4 e) LRBRL). Se acogen aquí dos posibilidades de gestión indirecta. Una de ellas es la expresión en el Ordenamiento jurídico local del fenómeno asociativo empresarial o fenómeno cooperativo, consistente (art. 1 de la Ley 3/1987, de 2 de abril, General de Cooperativas, en adelante LCo) en la agrupación societaria de "personas [cinco como mínimo] que tienen intereses o necesidades socio-económicas comunes, para cuya satisfacción y al servicio de la comunidad se desarrollan actividades empresariales, imputándose los resultados económicos a los socios, una vez atendidos los fondos comunitarios, en función de la actividad cooperativizada que realizan». La otra posibilidad es la que aquí nos interesa. Constituye una variante del modo reseñado como de gestión directa: sociedad mercantil en la que junto a la Entidad local existan otros titulares del capital social; no se precisa la proporción que deba existir entre estas titularidades distintas, por lo que parece admitir cualquiera, por mínima que sea la participación de la Corporación en el capital de la sociedad. Por eso, se trata realmente de una variante amplia, en ocasiones puramente cuantitativa, de las empresas públicas unipersonales de las que hablábamos en la gestión directa. En cualquier caso, sea mucha o poca la participación pública, el resultado es lo que se conoce como empresa mixta, integrada por capital privado y por capital público local, también conformadora, con desigual importancia, del sector público local. 
El dato que mejor puede orientar sobre la distinta operatividad de estos supuestos diversos de empresas públicas locales, por encima de la mera calificación legal como directa o indirecta de la gestión del servicio que realizan, viene dado por el mayor o menor grado de intervención posible de la Corporación (vía controles, directivas de actuación empresarial, etc.) en la conformación de la vida de la sociedad, lo que está íntimamente ligado al hecho de que el conjunto de acciones en manos públicas sea o no mayoritario.

Puede destacarse la virtualidad de estas fórmulas en tanto en cuanto vinieron a suponer un paso adelante en la evolución del actuar de las Administraciones públicas, superando ampliamente en la práctica a otras técnicas, como la de la descentralización funcional operada a través de la constitución de Organismos autónomos locales, a los que el Reglamento de Servicios de las Corporaciones locales (aprobado por Decreto de 17 de junio de 1955, en adelante RS) denomina "fundación pública del servicio". Se trata en este caso de constituir una entidad relativamente independiente de la Corporación, en la medida en que cuenta con personalidad jurídica propia e independiente de la de ésta (lo que implica la existencia de una estructura administrativa peculiar del organismo definida en el acto constitutivo del mismo), así como con unos medios materiales y financieros igualmente propios, que determinan la existencia de un Presupuesto del organismo. A la Corporación local compete la facultad de constituir Organismos autónomos dependientes de la misma en una serie de supuestos más o menos reglados que contempla el art. 85 RS: cuando lo exija una ley, cuando se adquieran de los particulares bienes adscritos al cumplimiento de determinado fin o, por último, cuando así lo aconseje el adecuado desarrollo de las funciones de beneficencia, de cultura o de naturaleza económica ${ }^{9}$.

Los Organismos autónomos locales han dado un juego muy extendido, pero cuando se ha planteado la conveniencia de encontrar un más amplio y flexible campo de actuación, con innegables notas de competitividad empresarial, mediante la exclusión casi total de la actuación económica de los poderes públicos del estrecho margen jurídico-administrativo, se

9 Debe tenerse en cuenta que cl art. 145 de la Ley Reguladora de las Haciendas Locales (Ley 39/1988, de 28 de diciembre, en adelante LHL) extiende analógicamente el régimen estatal establecido por el art. 50 de la Ley General Presupuestaria (Texto Refundido aprobado por Real Decreto Legislativo 1091/1988, de 23 de septiembre, en adelante LGP) y al mismo tiempo que obliga a la distinción clasificatoria de los Organismos autónomos locales (de carácter administrativo, por un lado, y de carácter comercial, industrial, financiero o análogo, por otro), integra el Presupuesto de éstos en el Presupuesto General de la Corporación, de acuerdo con los criterios que sobre estructura del Presupuesto de las Entidades locales suministra el art. 148 LHL. 
ha acudido a esas otras fórmulas que, por paradójico que pudiera parecer, han tendido cada vez más a situar a la Administración al mismo (o muy próximo) nivel de los particulares, singularmente en el nivel del empresario particular. Son éstas las formas de sociedad mercantil. Pero ¿qué clase de sociedad? El Ordenamiento jurídico-mercantil presenta diversas soluciones y puesto que el art. 85 LRBRL no menciona ninguna concreta, sino que tan sólo habla, genéricamente, de «sociedad mercantil" y, específicamente en un supuesto, de "cooperativa» debemos ocuparnos, siquiera sea brevemente, de estas figuras, aunque sólo sea para poner de relieve su escasa o nula aptitud a los efectos de la gestión municipal de intereses económicos mediante el ejercicio de la actividad empresarial.

Se reconoce, en efecto, por la Ley la habilidad de la cooperativa para gestionar, de modo indirecto, servicios públicos. No obstante, surgen dudas razonables ${ }^{10}$ sobre la utilización, con carácter general, de estas forma societaria por las Entidades locales, dadas sus características en cuanto agrupación de agentes económicos (productores de bienes o prestadores de servicios) sustancialmente homogéneos y, además, en número no inferior a cinco (art. 7 LCo). Bastaría simplemente esta circunstancia para desaconsejar la forma cooperativa como medio de participación mínimamente flexible del Municipio en actividades económicas, pero cabe apuntar aún otros motivos de índole estrictamente legal.

Puede considerarse como obstáculo el dato fundamental, presente en la definición del concepto de cooperativa que da el art 1 LCo, de la responsabilidad económica personal de los socios, subsidiaria e ilimitada, por los resultados económicos negativos de la gestión. No parece deseable, pues, en una hipotética gestión deficitaria de la cooperativa el consiguiente traslado de esas obligaciones económicas, en mayor o menor medida según el volumen de los recursos propios de la cooperativa responsables en primer término, a la propia gestión económica de la Corporación (prescindiendo ahora de los inconvenientes legales de tipo presupuestario que presentaría una situación semejante). Pero siendo ésta, en definitiva, una simple cuestión de decisión política, de optar o no, según la situación política de mayorías y minorías en el Ayuntamiento, por asumir este riesgo, nos interesa más destacar todavía otros motivos de fondo por los que no parece conveniente la sociedad cooperativa.

\footnotetext{
10 Dudas expresadas por la doctrina mercantilista. Vid. Alberto ALONSO UREBA, La Empresa Pública. Aspectos jurídico-constitucionales y de Derecho Económico, Montecorvo, Madrid, 1985, pp. 479-484; del mismo autor, La sociedad mercantil de capital como forma de empresa pública local, Universidad Complutense, Madrid, 1988, pp. 85-88.
} 
En primer lugar, por la limitación genérica que se establece en el sentido de que las cooperativas no podrán realizar las actividades y servicios propios de las mismas con terceras personas no miembros - no socios de la cooperativa - salvo que así se autorice, atendiendo a circunstancias especiales, por la Dirección General de Cooperativas del Ministerio de Trabajo y Seguridad Social (art. 5 LCo). Este régimen supone, a todas luces, un condicionamiento de la actuación municipal, en absoluto acorde con las necesidades de la gestión empresarial, además de la perturbación que comporta la injerencia de la Administración central, desviándose así grandemente el centro de decisión hacia un órgano administrativo ajeno a la estructura local.

Finalmente, el catálogo legal de las clases posibles de sociedades cooperativas de primer grado (u originales, frente a las de segundo o ulterior grado, que son asociaciones de cooperativas para constituir una que las agrupe a todas) relacionadas en el art. $116 \mathrm{LCo}$, ofrece un margen en exceso estrecho respecto al ámbito de las actividades que pueden desarrollar. De manera que de las cooperativas previstas, y viables (al no excluir la participación de personas jurídicas), a saber: Cooperativas de Viviendas, Agrarias de Explotacion Comunitaria de la Tierra, de Servicios, del Mar, de Transportistas, de Seguros, Sanitarias, de Enseñanza, y de Crédito, así como del estudio de los arts. 129-147 LCo, que regulan cada una de estas clases, se desprende el alcance tremendamente limitado que pueden tener para las actividades que consideramos.

En consecuencia, excluida la forma cooperativa, la mención que, tanto para la gestión directa como para la indirecta, se hace del resto de sociedades mercantiles en general, nos conduce a una interpretación conjunta de LRBRL y TRRL, y aun de lo que pueda entenderse subsistente de RS (en todo lo que no se oponga a aquéllas), que determina la exclusión de las sociedades colectiva y comanditaria, por cuanto, como sociedades mercantiles de tipo personal, no se ajustan a las previsiones legales sobre gestión de la sociedad por, o con participación de, las Corporaciones locales.

Son entonces las denominadas sociedades capitalistas, caracterizadas de modo principal por la participación de los socios en su capital y no por la propia persona de éstos, las que mejor acomodo encuentran: sociedad anónima y sociedad de responsabilidad limitada. Siendo la anónima el prototipo de estas sociedades de capital y la de responsabilidad limitada tan sólo una modulación de aquélla, resulta obligado centrar nuestra atención en la sociedad anónima, sabiendo que la regulación de ésta es esencialmente idéntica a la de la otra, con la sola precisión de que el régimen de la sociedad de responsabilidad limitada 
está pensado, por su menor complejidad, para la gestión, más rápida y flexible, de las empresas de tipo pequeño o medio. A pesar del acercamiento entre los regímenes de ambas que ha supuesto la reforma de la legislación mercantil de sociedades (por la eliminación del tope máximo al capital social de las de responsabilidad limitada y otras circunstancias no menos importantes), lo cierto es que todavía el patrón de la sociedad de responsabilidad limitada se sigue ajustando mejor, por su mayor flexibilidad (reducido capital social mínimo, regulación de las participaciones, etc), a la realidad de la pequeña y mediana empresa.

La experiencia, en fin, avala estas afirmaciones, puesto que es constante el recurso por parte de las Administraciones públicas al Ordenamiento jurídico privado cuando quieren realizar actividades económicas en forma y con caracteres de empresa. E igualmente constante es la configuración en estos casos de sociedades anónimas, como medio típico que son de la actividad mercantil de naturaleza capitalista 11 .

\section{ASPECTOS JURIDICO-FORMALES}

Una vez explorados en las líneas anteriores tanto los fundamentos legales como las posibles razones prácticas de la elección de la forma jurídica de sociedad anónima, pasamos en este momento a desarrollar esquemáticamente los aspectos procedimentales, esto es, los pasos que deben seguirse para la constitución de la misma por el Municipio y para su efectiva entrada en el tráfico jurídico-mercantil. Es indudable que el procedimiento se articula en dos grandes fases, jurídico-pública la primera y jurídico-privada la segunda, reflejando los dos mundos jurídicos que se concilian en el término "empresa pública», si bien es igualmente evidente que esa dicotomía Derecho privado-Derecho público responde en este caso -antes que al mantenimiento de una explicación del par de conceptos privado-público en condiciones de estricta separación, cuya vigencia en la doctrina ha sido ya completamente arrumbada - a las necesidades de la descripción lógica de los diversos requisitos cuya cumplimentación, por mandato legal, debe sucederse en el tiempo. Por otra parte, el contenido sustantivo subyacente a los requisitos que englobamos en el procedimiento jurídico-mercantil (que seguirán tanto las sociedades públicas como las privadas) presenta, en ocasiones nada despreciables, particularidades que vienen impuestas por la titularidad pública como tendremos ocasión de ver.

\footnotetext{
11 Para una completa panorámica de las formas de la empresa pública incluida la local, en los Derechos español y europeos, con atención al proceso histórico de tipificación de las mismas y explicación de las razones del predominio de la sociedad anónima, vid. ALONSO UREBA, op. cit., 1985, pp. 421-478.
} 
A) Procedimiento administrativo general para la iniciación de actividades económicas.

En primer lugar, debe tenerse en cuenta que existe una serie de exigencias procedimentales que debe ser cumplimentada en todo caso para la realización de actividades económicas por el Ayuntamiento, con independencia de la forma jurídica por la que se opte. Tras la amplia aplicación al ámbito local de la iniciativa pública económica que opera el art. 96 TRRL en los términos ya comentados, el art. 97 establece los requisitos para el ejercicio de actividades económicas por las Entidades locales. A ellos vamos a referirnos por el orden cronológico-jurídico en que deben ser cumplidos.

Son éstos los requisitos establecidos para el ejercicio de actividades económicas conforme al art. 128, pfo. $2 \mathrm{CE}$, mediante expediente acreditativo de la conveniencia y oportunidad de la medida, por las Entidades locales (art. 86, pfo. 1 LRBRL), pues no se olvide que en cualquier caso la programación y la ejecución del gasto público debe responder (art. 31, pfo. $2 \mathrm{CE}$ ) a los criterios de eficiencia y economía, que obligan a ponderar adecuadamente todas aquellas medidas que supongan desembolso o compromiso de recursos posibles. Obligación que alcanzará a los Municipios en la situación que venimos considerando, de donde se desprende no sólo la necesidad sino también la utilidad del expediente acreditativo de la conveniencia y oportunidad de la decisión desarrollado a través de las actuaciones que pasamos a considerar.

1) Designación de una Comisión de estudio compuesta por miembros de la Corporación y por personal técnico. Nada se dice respecto de la competencia para el nombramiento de esta Comisión, que debe entenderse atribuida al Alcalde por virtud de la cláusula residual, según la cual le corresponderán aquéllas que la legislación estatal o autonómica asignen al Municipio y no atribuyan a otros órganos municipales (en este sentido, arts. 21, pfo. 1 letra m) LRBRL y 41, pfo. 27 del Reglamento de Organización, Funcionamiento y Régimen Jurídico de las Entidades locales, aprobado por Real Decreto 2568/1986, de 28 de noviembre, en adelante ROF). En cuanto a la composición de la misma, no se imponen condiciones sobre el número y cualidad de sus miembros, por lo que uno y otra se dejan a la libre apreciación del Alcalde, quien tendrá cabalmente en cuenta las circunstancias del asunto en concreto a la hora de elegir a quienes hayan de formar parte de la Comisión. La finalidad de ésta (estudio de los aspectos social, jurídico, técnico y financiero de la actividad económica de que se trate) puede determinar una hipotética propuesta de composición. Así, puede pensarse en el Alcalde, el Secretario, el Interventor y el Tesorero de la Corporación, junto con los miembros de la Corporación cuya participación 
pueda ser interesante por razón del cargo que desempeñen, cual es el caso de los miembros de la Comisión Especial de Cuentas prevista en los arts. 116 LRBRL y 127 ROF. Junto a ellos también se prevé la participación del personal técnico que se crea conveniente, que podrá ser tanto personal propio de la Corporación como expertos ajenos a la misma, entre los que pueden resultar de especial interés un abogado y un economista.

2) Acuerdo inicial sobre el ejercicio de iniciativa pública económica en esa actividad económica, en relación con el contenido de la misma. Según las mismas normas de competencia antes citadas, corresponde adoptar este acuerdo al Alcalde. Puede tenerse en cuenta igualmente la atribución al Alcalde por los arts. 21, pfo. 1, letra d) y 41, pfo. 6 ROF de la función de impulsar los servicios municipales (además de por diferencia con la aprobación definitiva del expediente, que se atribuye expresamente al Pleno).

3) Elaboración por la Comisión de una Memoria relativa a los aspectos social, jurídico, técnico y financiero de la actividad económica de que se trate, determinándose la forma de gestión elegida de entre las previstas por la ley: gestión directa o gestión indirecta.

4) Sometimiento de la Memoria a un período de información pública, que tendrá como mínimo la duración de treinta días naturales, en el que existirá la posibilidad de que los particulares o las entidades que lo estimen necesario formulen observaciones o alegaciones sobre el contenido de la memoria, en cualquier caso no vinculantes para la Corporación.

5) Aprobación definitiva por el Pleno, mediante mayoría simple de los miembros presentes (más votos afirmativos que negativos de entre los votos realmente emitidos), según la regla general establecida por los arts. 47, pfo.1 LRBRL y 99, pfo.1 ROF, puesto que no se prevé la necesidad de ninguna mayoría especial para la aprobación de este expediente. Pueden introducirse modificaciones en algún extremo del proyecto, si resultan de la aceptación de propuestas que hayan sido formuladas en el período de información pública. Si se trata de innovaciones introducidas por propia voluntad de la Corporación sobre el texto inicialmente considerado, es verosímil la apertura de un nuevo período de información pública. Por otro lado, la no inclusión de las observaciones formuladas durante la información pública en el texto definitivamente aprobado es libre, según la apreciación del órgano encargado de otorgar la aprobación definitiva, que no está obligado a contestar las alegaciones realizadas ni a justificar su no aceptación. 
Hasta aquí lo que puede considerarse como régimen general preceptivo del procedimiento administrativo que debe seguir el Ayuntamiento para la iniciación de actividades económicas sea cual sea la forma jurídica que se pretenda adoptar para la ejecución de las mismas, a lo que debemos añadir resumidamente los pasos legales previstos para la constitución a aquellos efectos de una sociedad mercantil anónima, junto con algunas otras consideraciones.

En principio, la posibilidad misma de existencia de las sociedades anónimas públicas, fuera del Ordenamiento local, se recoge ya en el art. 14, pfo. 2 de la Ley de Sociedades Anónimas (Texto Refundido aprobado por Real Decreto Legislativo 1564/1989, de 22 de diciembre, en adelante LSA), que excepciona, para el caso de sociedades constituidas por entes públicos, la exigencia general de un mínimo de tres socios fundadores. A partir de aquí, como ya avanzamos, no vamos a distinguir básicamente entre la sociedad unipersonal (el Ayuntamiento es el único socio) y la sociedad mixta (el Ayuntamiento participa junto con otros socios), determinantes, respectivamente, de que la actividad se realice, según la clasificación conocida, de forma directa o indirecta, sino que atenderemos al régimen legal sustantivo común a ambas.

Así, dos soluciones permitidas son la entrada de la Corporación en una sociedad anónima ya constituida mediante la adquisición de todo o parte de su capital. No obstante, la situación que estamos considerando se enfoca más bien hacia la fundación de una nueva sociedad anónima por el Ayuntamiento actuando éste de promotor fundador. Para ello deberá seguirse primeramente en todas sus fases el procedimiento de ejercicio de la iniciativa pública económica anteriormente descrito, teniendo en cuenta que en el caso de que se proponga en la Memoria elaborada por la Comisión de estudio la gestión indirecta mediante sociedad anónima de economía mixta se incluirá en la misma el programa de fundación de la sociedad con el contenido que señala el art. 20 LSA, en especial, el texto literal de los Estatutos. Una vez otorgada por el Pleno la aprobación definitiva del expediente, tendrá que ponerse en marcha el procedimiento mercantil propio de constitución de una sociedad anónima, al que remiten con carácter general tanto el art. 103 como el art. 104 TRRL, esto es, tanto para la sociedad unipersonal como para la mixta.

La legislación mercantil acoge dos vías de fundación: en un solo acto por convenio entre los fundadores (fundación simultánea) o por suscripción pública de las acciones (fundación sucesiva), que son formas distintas para que se suscriba el capital de la sociedad, bien en un único momento mediante el acuerdo de los interesados, bien abriendo la posibilidad de que adquiera acciones todo aquel que lo 
desee, entendiéndose en cualquier caso constituida la sociedad desde su inscripción en el Registro Mercantil (art. 7 LSA). Para la sociedad unipersonal sólo cabrá lógicamente la fundación simultánea, pues es el Ayuntamiento el que se hace con todas las acciones, situación para la cual prevé el art. 89, pfo. 3 RS que el capital habrá de ser íntegramente desembolsado desde el momento de la constitución (excepcionando así la aplicación del art 12 LSA, que sólo requiere el desembolso efectivo, el pago, de la cuarta parte del valor nominal de las acciones, que sí deben, en cambio, estar totalmente suscritas, comprometidas, en el momento de la constitución) y establece el art 103, pfo. 1 TRRL que «...en la escritura de constitución constará el capital..., la forma de constituir el Consejo de Administración y la determinación de quienes tengan derecho a emitir voto representando el capital social». Para la sociedad mixta, a tenor del art. 104, pfo. 2 TRRL, será posible la fundación por cualquiera de las dos vías: simultánea, en la que actúen de común acuerdo la Corporación y empresarios particulares interesados en la constitución de la nueva sociedad; pero también cabe la fundación sucesiva, en la que la Corporación actúe de promotor, convocando previamente a la puesta en marcha de todo el procedimiento un concurso para que los ciudadanos formulen, sobre las bases fijadas, "propuestas respecto a la cooperación municipal y a la particular en la futura Sociedad, fijando el modo de constituir el capital social y la participación que se reserve la Entidad local en la dirección de la Sociedad y en sus posibles benefcios o pérdidas y demás particulares que figuren en la convocatoria», propuestas de las que pueden resultar los particulares que estén interesados en participar junto a la Corporación en la nueva sociedad anónima. Sea una u otra la vía de fundación de la sociedad mixta, obliga igualmente el art 109, pfo. 2 RS al desembolso desde la constitución del total del capital suscrito por la Corporación.

\section{B) Procedimiento jurídico-mercantil de constitución de una sociedad anónima pública.}

Así desarrolladas todas las fases del procedimiento de ejercicio de la iniciativa pública económica, en las que quede decidido tanto el tipo de sociedad anónima como la vía de fundación que se elige, sólo restarán para la efectiva constitución de la misma los pasos genéricamente previstos en la LSA, a los que nos referimos a partir de aquí, mencionando especialmente las modulaciones impuestas por la titularidad pública.

1) Depósito, caso de existir (fundación sucesiva de sociedad mixta), del programa de fundación, junto con un informe técnico sobre la viabilidad de la sociedad y un folleto informativo en la Comisión Nacional 
del Mercado de Valores (art. 21 LSA, conforme a lo establecido en los arts. 26 y 28 de la Ley 24/1988, de 28 de julio, del Mercado de Valores).

2) Depósito, tanto del programa como del folleto, en el Registro Mercantil, con la consiguiente publicación del mismo en el Boletín Oficial del Registro Mercantil (art. 21 LSA).

3) Suscripción de acciones durante el plazo fijado en el programa, mediante el desembolso efectivo por parte de los accionistas de al menos la cuarta parte del valor nominal del capital que suscriban (art. 22). Se dispondrá de un mes, desde el final de la suscripción, para formalizar ante Notario lista definitiva de los sucriptores, con indicación de las características de las acciones que correspondan a cada uno.

4) Celebración de la Junta Constituyente, en el plazo máximo de seis meses desde el depósito efectuado en el Registro Mercantil, que tomará los acuerdos a que se refiere el art. 25 LSA, señaladamente la aprobación de los Estatutos sociales y el nombramiento de las personas encargadas de la administración de la Sociedad.

5) Otorgamiento, ante Notario, de la escritura pública de constitución de la sociedad, en el plazo de un mes desde la celebración de la Junta Constituyente (art. 29 LSA) o, en el caso de que se trate de una sociedad anónima unipersonal o de una sociedad mixta de fundación simultánea, desde la aprobación definitiva del expediente de ejercicio de la iniciativa pública económica. Sobre el contenido de la escritura, ya hemos mencionado lo que prevé el art. 103, pfo. 1 TRRL, que sólo exige la inclusión en la misma de unos datos especialmente relevantes sobre capital y administración, por lo que, sin perjuicio de la amplia autorización que, en las sociedades mixtas, ofrece el art. 104, pfo. 2 TRRL para establecer «las especialidades internas tanto estructurales como funcionales que ...exceptúen la legislación societaria aplicable en la medida necesaria para promover y desarrollar la empresa», debemos entender preceptivo el contenido de la escritura que marca el art. 8 LSA, en el cual destaca la inclusión de los Estatutos que han de regir el funcionamiento de la sociedad, sobre los que volveremos inmediatamente. Conviene llamar la atención sobre la vital importancia de este artículo, que trata de consagrar, en el momento de constitución de la sociedad, el principio de legalidad y el principio de seguridad jurídica, obligando a la exacta determinación desde el mismo nacimiento de la sociedad de todos los mecanismos y factores esenciales que van a regir la vida social, teniendo en cuenta, además, las mayorías cualificadas (tres cuartas partes del número estatutario de votos, o mayoría absoluta) que exigen, respectivamente, los arts. 107 RS y 144 y 103 LSA para cualquier modificación de los Estatutos, con la posibilidad, incluso, de que éstos aumenten los quórum y mayorías legalmente previstas. 
Con independencia de lo que luego diremos, nos detenemos tan sólo en la indicación, en la escritura de constitución, de las aportaciones (en metálico o en bienes o en derechos evaluables económicamente, art. 36 LSA) que cada socio realice o se obligue a realizar en relación a su vez con el número de acciones que cada uno reciba por ello. A la hora de constituir la sociedad, el Ayuntamiento puede decidir materializar su aportación, total o parcialmente, en bienes, lo que remite a considerar qué bienes, y cómo, puedan ser objeto de aportación. Se han planteado en ocasiones problemas por la negativa del Registro Mercantil a efectuar la inscripción de sociedades a las que la Entidad local aportaba, debidamente valorados, bienes que tenían la condición de bienes de dominio público. La hipotética aportación de bienes de dominio público ha sido discutida con amplitud desde la Resolución de la Dirección General de los Registros y del Notariado de 12 de septiembre de 1985, en respuesta al recurso interpuesto por el Ayuntamiento de Las Palmas contra la denegación de la inscripción en el Registro Mercantil de la "Empresa Municipal de Aguas de Las Palmas, Sociedad Anónima», dada la aportación a la misma por el Ayuntamiento de bienes de dominio público (aguas, presas, canales, conducciones...).

En vista de estos datos, las soluciones doctrinales parecen inclinarse mayoritariamente por la imposibilidad de tal aportación, con diversos fundamentos ${ }^{12}$, entre los cuales podemos mencionar aquí la desvirtuación que supondría del régimen de responsabilidad patrimonial de la sociedad anónima: puesto que el sentido de la misma estriba en que con sus bienes, sólo con ellos, se pueda hacer frente a las deudas sociales, no se entiende que haya unos bienes que, por ser demaniales, escapen a esa regla, al estar excluidos del comercio. En efecto, son características constitucionales (art. $132 \mathrm{CE}$ ) de los bienes de dominio público su inalienabilidad e inembargabilidad, lo que impediría precisamente que fueran utilizados para hacer frente a las deudas sociales, exclusión que no casa bien con la esencia de la anónima. Se admitiría en esos mismos casos, no obstante, la titularidad por parte de la empresa de derechos reales, no dominicales, sobre bienes de dominio público (como por ejemplo la concesión administrativa). Con todo, existen también posturas favorables a considerar válida la aportación de bienes demaniales ${ }^{13}$.

12 Vid. los expuestos por Pablo MENENDEZ GARCIA, "Sociedad privada municipal y aportación de bienes de dominio público", Revista Española de Derecho Administrativo núm. 47, 1985, pp. 419-424; ROMERO HERNANDEZ, "La empresa privada municipal y los bienes de servicio públicon, Ibid., pp. 377-394; ALONSO UREBA, op. cit., 1988, pp. 141-143; y Francisco LLISET BORRELL, La actividad empresarial de los Entes locales, Publicaciones Abella, Madrid, 1990, 133-136.

13 Por ejemplo, Angel Luis MONGE GIL, «La aportación de bienes de dominio público a la sociedad privada municipal (comentario a la resolución de la D.G.R.N. de 12 de septiembre de 1985)", Revista de Derecho Mercantil núm. 181-182, 1986, pp. 467-494. 
A efectos prácticos, en conclusión, para clarificar la situación más allá de planteamientos doctrinales, podemos señalar que no hay que centrar la discusión tanto en la calificación jurídica de los bienes que puede decidir aportar el Municipio cuanto en el procedimiento que para ello debe seguirse, aun con las mismas consecuencias finales, distinguiendo según se trate de bienes públicos o patrimoniales ${ }^{14}$. Por tanto, de considerarse por el Municipio una aportación de este tipo sería preciso que operara la previa desafectación del uso o servicio a que estuviera destinado ese bien, mediante el correspondiente procedimiento que contempla la normativa local (arts. 8 y concordantes del Reglamento de Bienes de las Entidades locales, aprobado por Real Decreto 1372/1986, de 13 de junio, en adelante RB), que exige expediente previo en el que se acredite la oportunidad y legalidad de la alteración de su calificación jurídica, aprobado por mayoría absoluta. Desafectación que supondrá su conversión en bienes patrimoniales o, según la calificación tradicional, bienes propios de la Entidad (si bien no dejan de suscitarse algunos problemas a propósito del mecanismo técnico conforme al cual debiera realizarse esa aportación). En cualquier caso, será exigible el informe pericial a cargo de los expertos designados por el Registro Mercantil, que constará como anexo a la escritura, al que se refiere el art. 38 LSA, describiendo y valorando los bienes aportados.

6) Inscripción de la escritura, en el plazo de dos meses desde su otorgamiento, en el Registro Mercantil que corresponda al domicilio de la sociedad (art. 29 LSA), momento a partir del cual se entiende constituida y goza de personalidad jurídica (art. 7 LSA), con la subsiguiente publicidad de la inscripción en el Boletín Oficial del Registro Mercantil.

\section{ALGUNAS CUESTIONES DE INTERES EN TORNO AL FUN- CIONAMIENTO DE LA SOCIEDAD}

Analizadas hasta aquí las posibles vías de acceso de la Corporación al sector público económico a través de sociedades mercantiles de capital, singularmente a través de sociedades anónimas, fundadas por alguno de los cauces legales apuntados y ya sea con la Corporación como único socio o compartiendo ésta el capital social con otros socios, tenemos que añadir todavía algunas precisiones sobre el régimen de funcionamiento y organización de estas sociedades, manteniendo la voluntad de considerar conjuntamente tanto el de aquellas que supongan realizar la gestión de la actividad de forma directa como el de aquellas que pudieran hacernos hablar, formalmente, de gestión de

14 ALONSO UREBA, op cit, 1988, pp. 139-160. 
modo indirecto. Haremos estas consideraciones, sin ninguna pretensión de exhaustividad, al hilo de las menciones que, con gran detalle según el art. 9 LSA, deben hacerse constar en los Estatutos, incluso reiterando, a efectos sistemáticos de claridad, algunos comentarios. Establece el citado precepto lo que sigue «En los Estatutos que han de regir el funcionamiento de la sociedad se hará constar:

a) La denominación de la sociedad.

b) El objeto social, determinando las actividades que lo integran.

c) La duración de la sociedad.

d) La fecha en que dará comienzo a sus operaciones.

e) El domicilio social, así como el órgano competente para decidir o acordar la creación, la supresión o el traslado de las sucursales.

f) El capital social, expresando, en su caso, la parte de su valor no desembolsado, así como la forma y el plazo máximo en que han de satisfacerse los dividendos pasivos.

g) El número de acciones en que estuviera dividido el capital social; su valor nominal; su clase y serie, si existieren varias, con exacta expresión del valor nominal, número de acciones y derechos de cada una de las clases; el importe efectivamente desembolsado; y si están representadas por medio de títulos o por medio de anotaciones en cuenta. En caso de que se representen por medio de títulos, deberá indicarse si son nominativas o al portador y si se prevé la emisión de títulos múltiples.

h) La estructura del órgano al que se confía la administración de la sociedad, determinando los Administradores a quienes se confiere el poder de representación, así como su régimen de actuación, de conformidad con lo dispuesto en esta Ley y en el Reglamento del Registro Mercantil. Se expresará, además, el número de Administradores, que en el caso del Consejo no será inferior a tres, o, al menos, el número máximo y el mínimo, así como el plazo de duración del cargo y el sistema de su retribución, si la tuvieren.

i) El modo de deliberar y adoptar sus acuerdos los órganos colegiados de la sociedad. 
j) La fecha de cierre del ejercicio social. A falta de disposición estatutaria, se entenderá que el ejercicio social termina el 31 de diciembre de cada año.

k) Las restricciones a la libre transmisibilidad de las acciones, cuando se hubiesen estipulado.

l) El régimen de las prestaciones accesorias, en caso de establecerse, mencionando expresamente su contenido, su carácter gratuito o retribuido, las acciones que lleven aparejada las obligación de realizarlas, así como las eventuales cláusulas penales inherentes a su incumplimiento.

m) Los derechos especiales que, en su caso, se reserven los fundadores o promotores de la sociedad".

A la vista está el extraordinario detallismo estatutario, incrementado notablemente respecto a la anterior Ley (de 1951, recuérdese), con el que se pretende garantizar al máximo los aludidos principios de legalidad y de seguridad jurídica. Pasamos, pues, a continuación, a formular ciertas precisiones sobre algunos de estos extremos del contenido estatutario.

\section{A) Denominación.}

La denominación de la sociedad, en la que debe figurar la indicación "Sociedad Anónima» o "S.A.», no puede ser idéntica a la de una ya existente (art. 2 LSA), por lo que cuando el Ayuntamiento fundador (en la fundación simultánea de la sociedad) o promotor de la fundación sucesiva se disponga a otorgar ante Notario la escritura de la sociedad deberá cerciorarse de este requisito, pues de lo contrario topará con la negativa, tanto del Notario primero como del Registrador después, a autorizar el uno e inscribir el otro la sociedad (art. 372 del Reglamento del Registro Mercantil, aprobado por Real Decreto 1597/1989, de 29 de diciembre, en adelante RM). Los criterios que inducirían a hablar de denominación idéntica (utilización de las mismas palabras en diferente orden...) vienen descritos en el art $373 \mathrm{RM}$.

\section{B) Objeto social.}

Es imprescindible la fijación del objeto social, de la actividad que se propone desarrollar la sociedad. Parecería aconsejable la descripción del objeto social en términos preferiblemente amplios, lo cual no quiere 
decir tanto que deba ser imprecisa cuanto que sea susceptible de satisfacer las diversas necesidades que el Municipio pretenda atender mediante su actuación o participación en forma de sociedad anónima en determinadas actividades empresariales. Dicha cautela vendría sugerida por la finalidad de garantizar un amplio y flexible campo de actuación que haga eficaz la intervención pública, intentando neutralizar la legitimación que recogen los artículos 115 y siguientes LSA para la impugnación, en diversas circunstancias, de los acuerdos sociales que se opongan a los Estatutos (p.ej. actividades sociales que pudieran no encajar en la descripción del objeto social fijado en éstos) o lesionen los intereses de la sociedad.

A propósito de este problema de la mayor o menor indefinición del objeto social, resulta de interés la Sentencia del Tribunal Supremo (Sala Tercera) de 10 de octubre de $1989^{15}$, relativa a la empresa «Iniciativas S.A., Iniciatives Municipals Empresarials, Sociedad Privada Municipal», constituida por el Ayuntamiento de Barcelona en 1985 16. La Sentencia anula el acuerdo del Ayuntamiento por el cual se aprobaba la constitución de la empresa, basándose precisamente para ello en «...la ambigüedad, la inconcreción, la vaguedad, la generalidad, la imprecisión, la indefinición y la indeterminación de la concreta o concretas actividad o actividades que hubiese de desarrollar la nueva Sociedad; pues son prácticamente posibles todos los negocios y actividades dentro del omnicomprensivo enunciado general que reseña el objeto social... que no especifica ninguna concreta actividad o negocio que se vaya a realizar, sino sólo los indicados enunciados generales» (Fundamento Jurídico Sexto).

Sobre la incorrección de esta Sentencia se ha pronunciado ya, con contundencia, la doctrina ${ }^{17}$, evidenciando la completa falta de fundamento legal de la decisión, por venir apoyada en valoraciones y juicios de oportunidad (no de legalidad), que en absoluto corresponde formular a la jurisdicción, sino a los responsables políticos en la materia. En efecto, a la luz del texto de la nueva LSA, parece claro que la definición del

\footnotetext{
15 Repertorio Aranzadi 7352.

16 A título de curiosidad, las condiciones y motivos que justificaron la puesta en marcha de la empresa, muy enlazadas con las consideraciones que venimos realizando, son explicadas por el Alcalde Pasqual MARAGALL, «La descentralización del sector público en la superación de la crisis del Estado del Bienestar" en Josep MIR I BAGO (Ed.), Crisis Económica y Estado del Bienestar, Instituto de Estudios Fiscales, Madrid, 1989, pp. 279-282.

17 SOSA WAGNER, "Comentario a la desafortunada Sentencia del Tribunal Supremo de 6 de septiembre de 1989 (Asunto, empresa municipal de Barcelona "Iniciatives»)", Poder Judicial núm. 19, pp. 309-312.
} 
objeto social debe hacerse sólo, y exactamente, "determinando las actividades que lo integran" ("determinación precisa y sumaria», dice el art. 117 RM, que añade otras reglas), es decir, enumerando cuáles sean tales actividades, como ocurría en la descripción, ciertamente amplia ${ }^{18}$, del objeto de la empresa barcelonesa. Lo que, por otra parte, ya venía siendo aceptado, a efectos de permitir la válida inscripción registral de la sociedad, por la Dirección General de los Registros y el Notariado, bajo la vigencia de la anterior Ley de 1951, que no añadía esa coletilla, sino que se limitaba a exigir, sin más, la constancia en los Estatutos del objeto social.

Sin embargo, parece subsistir cierta tendencia en cuya lógica encajaría el sentido del fallo comentado ${ }^{19}$, en conexión con el principio de especialidad o de adherencia al fin al que están sujetas las personas jurídicas, "que exige - reza el Fundamento Jurídico Séptimo de la Sentencia-determinar con rigor y precisión el objeto de la empresa pública y la actividad o negocio que ella deba realizar». Sin embargo, el citado principio ${ }^{20}$, que por otra parte carece de plasmación legal alguna, sólo acaba suponiendo una obviedad jurídica, sin contenido jurídico preciso

18 Los Estatutos de «Iniciatives», según el texto que figura en el Fundamento Jurídico Cuarto de la Sentencia, establecen como objeto social «...la promoción, refuerzo y participación en actividades económicas que contribuyan al desenvolvimiento del entorno socio-económico, potenciando iniciativas generadoras de riqueza y ocupación", añadiendo seguidamente una lista de actividades comprendidas en ese objeto: "Promoción de iniciativas empresariales. Servicios y funciones de asesoramiento y de estudio en general. Elaboración de planes de viabilidad, de reconversión y de industrialización. Participación económica en proyectos empresariales. Participación no financiera en el desarrollo de iniciativas empresariales y sociales. Facilitar y participar en operaciones de capitalriesgo. Canalizar y gestionar directa o indirectamente los diversos tipos de ayudas, subvenciones y créditos normales o especiales, así como las ventajas que puedan existir de programas de fomento de la ocupación, de formación y de otros tipos, de interés para los proyectos que se desarrollen. Gestionar todo tipo de instrumentos y trámites necesarios para las actuaciones empresariales».

19 Así, aunque de forma un tanto confusa, LLISET BORRELL, op. cit., pp. 28, 59 y 60. Distinto parece ser el enfoque de SALAS HERNANDEZ, que a pesar de valorar positivamente la Sentencia lo hace por entender que "En definitiva, como cualquier Administración pública, las Corporaciones locales deben justificar que su actuación, incluso en el ejercicio de actividades económicas no publificadas, responde a una finalidad de interés público o general, en este caso, de la comunidad que está en la base de la correspondiente entidad local» (op. cit., p. 208), por lo que el Tribunal, al entender que no está suficientemente justificada «la conveniencia y oportunidad de la medida», sólo está aplicando la regla constitucional de que "La Administración pública sirve con objetividad los intereses generales...» (art. 103, pfo. $1 \mathrm{CE}$ ).

20 Vid., por ejemplo, la exposición que del mismo hace ARIÑO ORTIZ, "La empresa pública", en GARRIDO FALLA (Dir.), El modelo económico en la Constitución española, vol. II, Instituto de Estudios Económicos, Madrid, 1981, pp. 104-109. 
por sí mismo, como es el necesario respeto al derecho a la libertad de empresa y a la libre competencia, que, por supuesto, tampoco podrán ser conculcados por las empresas tras las cuales se encuentre la mano pública. Con vocación garantista, se insiste en este punto de manera excesiva en el límite y el control de la empresa pública, mediante la negación a ésta de cualquier privilegio por razón de su origen, posición en extremo acertada y aconsejable que, sin embargo, olvida hacer el mismo hincapié en la imposibilidad igualmente de que las empresas privadas ostenten privilegios y situaciones de favor frente a las públicas. Así lo proclaman tanto los límites en cuyo marco los poderes públicos deben promover y garantizar la libertad de empresa (art. $38 \mathrm{CE}$ : la economía de mercado, las exigencias de la economía general, la planificacion) como la rotunda afirmación que supone el art. 128, pfo. 2 en punto al reconocimiento de la iniciativa pública en la economía.

Sería oportuno recordar la interpretación conjunta de estos preceptos 21 que concluye en la inexistencia de prevalencia o subordinación alguna entre empresa pública y empresa privada, por la afirmación en la CE de un sistema de compatibilidad o de coiniciativa empresarial pública y pri$v a d a$, ya que «no hay sectores económicos que jurídicamente queden excluidos de la posible actuación pública», aunque sí es cierto que la iniciativa pública y la privada "discurren por cauces jurídicamente diferenciados, en base a títulos distintos» 22, que, sin embargo, no se concretan en ámbito material alguno, puesto que los casos de reserva al sector público de determinadas actividades, constitucionalmente prevista, constituyen la excepción a la regla general.

\section{C) Duración.}

La duración de la sociedad viene condicionada, para las sociedades unipersonales, por lo dispuesto en el art. 103, pfo. 2 TRRL sobre la obligatoria disolución de la sociedad cuando las pérdidas excedan de la mitad del capital social. Para las sociedades mixtas es aceptable

\footnotetext{
21 En este sentido, S. MARTIN-RETORTILLO, op cit., pp. 90-99; Oscar DE JUAN ASENJO, La Constitución Económica Española (Iniciativa económica pública "versus» iniciativa económica privada en la Constitución española de 1978), Centro de Estudios Constitucionales, Madrid, 1984, pp. 90-98.

22 S. MARTIN-RETORTILLO, loc. cit., p. 96. Régimen de posición de igualdad entre empresa pública y empresa privada que, por otra parte, y no es necesario insistir ahora en ello, se halla en perfecta sintonía con el Derecho comunitario europeo, en lo tocante a las restricciones impuestas tanto a las ayudas financieras nacionales como a las actuaciones que puedan perturbar la libre competencia empresarial.
} 
también la inclusión de cláusulas de este tipo o cualesquiera otras similares que se consideren necesarias para promover y desarrollar la empresa, exceptuando en lo que se crea conveniente la legislación mercantil de sociedades (arts. 260 y siguientes LSA, en punto a disolución y liquidación) al constituir la sociedad, según la amplia habilitación que al respecto ofrece el artículo 104, pfo. 2 TRRL, con el único límite de la salvaguarda de los intereses de los terceros que puedan verse afectados por esas previsiones. No obstante, el art. 111, pfo. 1 RS les marca un plazo máximo de cincuenta años: ¿puede considerarse vigente esta limitación? Intentaremos responder a este interrogante de índole estrictamente legal.

El art. 108 TRRL impone como límite máximo de duración de las formas indirectas de gestión el de cincuenta años. ¿Debemos entender comprendida en el mismo a la empresa mixta? En principio, no parece que debiera referirse a ella, sino a las otras formas, pues en preceptos anteriores ha dejado claramente reguladas las peculiaridades de ese procedimiento de gestión y ahora da las normas generales para el resto. Pero el art. 108 TRRL es tajante, al imponer esa obligación de duración máxima de cincuenta años "con la única excepción de los servicios concedidos", esto es, los gestionados por un particular al que se le ha otorgado la correspondiente concesión administrativa (que le confiere un determinado derecho de contenido económico de utilización de ciertos bienes públicos con la finalidad de regir la explotación o aprovechamiento necesario de éstos, mediante la entrega de una contraprestación igualmente económica en forma de canon satisfecho a la Entidad titular de esos bienes o servicios). En cualquier caso, no parece que exista inconveniente alguno para, una vez transcurrido el plazo y disuelta la sociedad, constituir una nueva absolutamente idéntica.

\section{D) Capital social.}

La indicación del capital social debe hacerse expresando el número de acciones en que estuviera dividido, así como las características de éstas según los tipos de acciones que permiten los arts. 47 y siguientes LSA. El capital mínimo exigido (art. 4 LSA) es de diez millones de pesetas. En este punto debe quedar clara la calificación jurídica que recibe la participación de la Corporación en el capital social, esto es, las acciones de las que sea titular el Ayuntamiento, asunto que puede inducir a error ${ }^{23}$.

23 Vid. las consideraciones, acertadísimas y muy interesantes, de ALONSO UREBA, op. cit., 1988, pp. 136-138, a propósito de la calificación jurídica de las acciones, así como de la incorrección técnica de la terminología empleada por la LRBRL al hablar de sociedades cuyo capital social "pertenezca", ya sea íntegra o parcialmente, a la Entidad local. 
Las acciones suscritas por la Entidad son bienes patrimoniales o propios de la misma, en cuanto susceptibles de producir ingresos para el erario de la Entidad y siempre que no estén destinadas a uso público ni afectadas a un servicio público, según la definición que da el art. 6 $\mathrm{RB}, \mathrm{y}$ análogamente a lo que prevén los arts. 100 y ss. de la Ley del $\mathrm{Pa}$ trimonio del Estado. Como tales bienes patrimoniales, las acciones del Ayuntamiento están sometidas al régimen jurídico de los mismos previsto especialmente en los arts. 21 pfo. 1 letra f), 80 y 82 LRBRL, 76, $80,86,87,113,122,123$ y 124 TRRL $, 6,9,10,17,18,23,32,33,34$, $35,37,43,70,71,92,112,114$ y $118 \mathrm{RB}, 29$ y 29 bis de la Ley de Contratos del Estado y 92 a 112 del Reglamento de Contratos del Estado, de los que se derivan algunas importantes obligaciones formales respecto a adquisición, custodia, inventario, enajenación, etc. de bienes patrimoniales, entre los que se incluyen los títulos mobiliarios que son las acciones.

Interesa destacar la necesidad de subasta pública para que el Ayuntamiento transmita sus acciones. Es decir, no es libre de enajenarlas como quiera y a quien quiera, sino que debe hacerlo por el procedimiento formalizado, presidido por las convenientes garantías de publicidad y libre concurrencia, que supone la subasta pública. Además, se reconoce la eventualidad de que los Estatutos recojan estipulaciones añadidas que restrinjan la libre transmisibilidad de las acciones.

Por otro lado, es fundamental no confundir estos bienes de la Entidad con los bienes que constituyan el patrimonio propio de la sociedad, sobre los que sólo ésta, y por los mecanismos sociales legalmente establecidos, puede disponer. Sólo los órganos de la sociedad y por los medios previstos en la LSA pueden actuar sobre el patrimonio social, que es independiente del de la Corporación; ésta sólo posee la cantidad, mayor o menor, de acciones que haya suscrito, sometidas en su utilización a las disposiciones citadas. De ahí la exigencia, no sólo conceptual, de abordar mínimamente el estudio del gobierno de la sociedad, sus órganos y sus reglas básicas de actuación.

\section{E) Organo de administración.}

Los Estatutos deben contener la estructura del órgano al que se confía la administración de la sociedad, así como el número de los administradores: en el momento de constitución deben determinarse ya las pautas esenciales que van a regir la organización y funcionamiento sociales. Según la LSA, la administración y gestión ordinaria de la sociedad puede llevarse a cabo de formas diversas: por dos administradores, nombrados por la Junta General, que actúen mancomunadamente, o 
por un Consejo de Administración (formado por tres o más personas, que actúan solidariamente en el seno de ese órgano colegiado); por otra parte, el Consejo de Administración puede designar de entre sus miembros una Comisión ejecutiva o uno o varios Consejeros-delegados, es decir, que desempeñen, con carácter permanente, facultades o funciones del Consejo que les son delegadas por éste (piénsese, por ejemplo, en un Gerente de la sociedad, posibilidad incluida por el art. 90 RS entre los órganos de dirección y administracion de la empresa).

Téngase en cuenta que las reglas que al respecto contienen los arts 93 a 143 LSA pueden ser excepcionadas en el acuerdo constitutivo de la sociedad, especialmente en cuanto a las sociedades de economía mixta, por aplicación del art. 104, pfo. 2 TRRL, "en la medida necesaria para promover y desarrollar la empresa" y siempre y cuando no se destruyan las cautelas pensadas para la protección de terceros.

Para las sociedades unipersonales, el art. 103, pfo. 1 TRRL exige la determinación en los Estatutos de la forma de constituir el Consejo de Administración. Está claro que en éstas últimas puede discutirse el papel de la Junta General, en cuanto que, como reunión del conjunto de los accionistas, coincidirá en su composición con el máximo órgano de gobierno de la Entidad, es decir, el Pleno del Ayuntamiento. No obstante, se ha defendido 24 la consideración separada de ambos, esto es; la subsistencia en estos casos de la Junta General, aunque se superponga o coincida con el Pleno, por la diversa significación que presentan, al tratarse de «órganos no sólo distintos sino de persona jurídica distinta", añadiendo que "la posibilidad de que los niveles de la Corporación se reencuentren, con diversidad de pareceres, en el órgano supremo de la sociedad, hace de la Junta General un órgano extremadamente útil y, por demás, un órgano en que el Municipio recobra, bajo formas de Derecho privado, sus esencias democráticas» 25 . Afirmaciones impecables desde el punto de vista teórico que, sin embargo, en la práctica pueden ser, cuando menos, discutibles, puesto que, en definitiva, no podrá ser nunca distinta la voluntad del Ayuntamiento Pleno de la del Ayuntamiento en cuanto único socio, ya que éste se expresa necesariamente a través de aquel órgano soberano. Por otro lado, se ha puesto de relieve ${ }^{26}$ el significado jurídico-privado de las funciones

${ }^{24}$ LLISET BORREL, op. cit.

25 Loc. cit., pp. 129 y 130.

26 ALONSO UREBA, op. cit., 1988, pp. 170-174. A este respecto, Justino F. DUQUE DOMINGUEZ puso ya de manifiesto la dicotomía del régimen jurídico de funcionamiento de la Junta General: régimen de procedimiento y adopción de acuerdos 
que actúe el Pleno de la Entidad en cuanto Junta General de la sociedad, puesto que el RS establece que la Entidad en sí misma asumirá las funciones de la Junta General.

Genéricamente, son de aplicación los arts. 90 a 94 y 106 a 108 RS para las sociedades locales unipersonales y mixtas, respectivamente, concretando algunos aspectos orgánicos de interés, entre los que resulta relevante la limitación, en el primer caso, del número de miembros del Consejo de Administración a un máximo de nueve o cinco según que el Municipio tenga más o menos de veinte mil habitantes, cuya mayoría (la mitad más uno) deberá estar constituida por miembros de la Corporación, Concejales, siendo el resto elegido entre técnicos o expertos (letrados asesores, economistas, representantes sindicales o empresariales, etc.). En el caso de sociedad mixta, la mitad de los puestos a que tenga derecho el Municipio en el Consejo de Administración será cubierta por miembros de la Corporación y la otra mitad por técnicos, ambos libremente elegidos por la Corporación. Se entiende asimismo que estos técnicos no tienen por qué ser personal al servicio de la Entidad, sino cualesquiera personas que reúnan las condiciones precisas de capacidad y cualifícación.

\section{F) Presupuestos y fiscalización.}

La Ley de las Haciendas Locales impone algunas importantes obligaciones formales en materia presupuestaria. Así, fundamentalmente, los arts. 145, 146, 147, 149, 181, 190, 193, 194, 201 y 204, que obligan, entre otras cosas, a la inclusión de los estados de previsión de ingresos y gastos de las sociedades unipersonales en el Presupuesto General anual de la Corporación, al que deben unirse como Anexo los programas de actuación, inversiones y financiación de cualquier tipo de sociedad en la que participe el Municipio (informaciones que, a estos efectos, tienen que suministrar las sociedades antes del día quince de septiembre de cada año) 27.

Se extiende a las sociedades públicas, con independencia del porcentaje de participación pública en las mismas, el mismo régimen de

conforme a la legislación local y las restantes cuestiones sociales conforme a la legislación mercantil («La Sociedad privada municipal», Revista de Estudios de la Vida Local, núm. 179, 1973, pp. 439-442).

27 Vid. la glosa que de estos preceptos se hace en la obra de José Ignacio RUBIO DE URQUIA, Ley Reguladora de las Haciendas Locales, El Consultor de los Ayuntamientos y los Juzgados, Madrid, 1989. 
contabilidad pública y de control interno y externo de la gestión económica que se diseña para la actividad presupuestaria de las Entidades locales.

Respecto a las formas de control interno (interventor, financiero y de eficacia, mediante procedimientos de auditoria pública), se ha destacado 28 la imperfección y la escasa efectividad de estas técnicas, que escapan por el momento al ámbito jurídico para situarse principalmente en el terreno de la política, por lo que se propugna, de lege ferenda, la traslación del régimen propio del control de legalidad al resultado de los controles económicofinancieros, lo que supondría implantar en los mismos técnicas jurídicas como la nulidad, la anulabilidad y la revocación, con el corolario consiguiente en materia de responsabilidad 29.

En cuanto al control externo, realizado por el Tribunal de Cuentas, "supremo órgano fiscalizador de las cuentas y de la gestión económica" de todo el sector público (arts. $136 \mathrm{CE}$ y 1 de la Ley Orgánica $2 / 1982$, de 12 de mayo, reguladora del Tribunal), concepto en el que se incluyen las empresas públicas (art. 4, pfo. $1 \mathrm{f}$ ) LOTCu), con independencia del alcance que en la práctica pueda llegar a tener dicho control, se plantea un problema de carácter más bien organizativo. Se trata de la existencia en algunas Comunidades Autónomas (Andalucía, Canarias, Cataluña, Comunidad Valenciana, Galicia, Islas Baleares, Navarra y País Vasco) de Organos fiscalizadores autonómicos, cuya competencia de control se extiende no sólo a la Administración de la Comunidad Autónoma, sino también a las Entidades locales comprendidas en su territorio. Nos encontramos entonces, por lo menos teóricamente, con la posibilidad de que se produzca un control doble, estatal y autonómico, de la actividad económica de las Corporaciones locales, situación profundamente insatisfactoria, carente de todo fundamento, ineficaz en la práctica y que, como se ha denunciado ${ }^{30}$, no ha sido corregida, habiendo ocasión para ello, ni por la legislación ni por la interpretación acogida en el Tribunal Constitucional. En efecto, ni la Ley 2/1982 (art. 1, pfo. 2) ni la posterior Ley de Funcionamiento del Tribunal de Cuentas (Ley 7/1988, de 5 de abril, en su art. 29) han suministrado criterios claros de articulación del Tribunal de Cuentas y

28 Alfonso PEREZ MORENO, "Garantías jurídicas en las Haciendas locales», Revista de Estudios de la Administración Local y Autonómica núm. 247, 1990, pp. 485-513.

29 Loc. cit., p. 512.

30 FANLO LORAS, Fundamentos..., op. cit., pp. 554-562; con anterioridad, el mismo autor se había pronunciado ya sobre este asunto: El Tribunal de Cuentas y las Corporaciones Locales, IEAL, Madrid, 1986, pp. 109 y ss. 
los Organos autonómicos similares con base en una delimitación de sus competencias respectivas en el control de las Entidades locales. Insuficiencia de regulación que ha venido a ser consagrada por las Sentencias del Tribunal Constitucional 187/1988, de 17 de octubre (sobre la Ley catalana de la Sindicatura de Cuentas) y 18/1991, de 31 de enero (sobre la Ley gallega del Consejo de Cuentas), conforme a las cuales es perfectamente constitucional la existencia de un control económico-financiero de la Comunidad Autónoma sobre las Corporaciones locales sin excluir tampoco el control que pueda realizar el Estado a través del Tribunal de Cuentas.

Es decir, por lo que ahora nos interesa, sin perder de vista esta criticable realidad así interpretada que podría evitarse por diversas vías ${ }^{31}$, es preciso destacar esa duplicidad de control externo que, por aplicacion en esos casos de la legislación autonómica correspondiente, supondrá atender a las obligaciones de suministro de información, etc. no sólo al Tribunal de Cuentas, sino también al Organo autonómico. De nuevo se echa en falta, he aquí un reflejo de lo mismo, la conexión de consecuencias jurídicas a los resultados de la fiscalización (o las fiscalizaciones, por lo que hemos visto) externa de la gestión económica.

\section{A MODO DE CONCLUSION}

El conjunto de estas reglas, técnicas y procedimientos que deben ponerse en juego a la hora de considerar por parte de cualquier Municipio la posibilidad y conveniencia de constituir una empresa, condicionan la forma en que debe, obligatoriamente, hacerlo. Una vez más destaca aquí, por encima de todo, el valor del procedimiento como marco que garantiza la correcta actuación, conforme a patrones estrictamente legales y no de capricho o de mera voluntad política, de una Administración pública. Ahí reside la grandeza de estas normas de Derecho Administrativo, que respetando profundamente el margen de libertad de decisión de toda institución pública somete, por imperio de la Ley, su expresión administrativa a unos cauces previamente delimitados y la hace, por lo tanto, controlable.

31 Vid. FANLO LORAS, op.cit, loc. cit., que propone como técnica fundamental para entender constitucionalmente correctas las fiscalizaciones de los Organos autonómicos, así como para evitar esa duplicidad competencial, la delegación por el Estado a esas Comunidades Autónomas, mediante Ley Orgánica del art. 150, pfo. $2 \mathrm{CE}$, las facultades de fiscalización sobre las cuentas de las Corporaciones locales correspondientes a las mismas. Buscando la mayor eficacia del Tribunal y la adecuada fiscalización de las cuentas locales, apuesta también por la descentralización, a través de los Servicios Provinciales de las Delegaciones de Hacienda, en aquellas Comunidades que carecen de Organos propios de fiscalización. 
Con independencia de las imperfecciones últimamente aludidas, debe valorarse lo que supone el que en la medida en que estos cauces jurídico-públicos no sean respetados por una actuación administrativa concreta, ésta podrá ser invalidada por los Tribunales, de acuerdo con los mecanismos de impugnación y anulación propios de la Jurisdicción Contencioso-administrativa 32 .

Es por ello por lo que las Entidades locales, muy directamente los gestores y las autoridades municipales, deben poner especial cuidado en el conocimiento y en el manejo adecuado del laberíntico panorama legal que ofrecen las técnicas y procedimientos de actuación en la vida económica.

Mayo de 1991

\footnotetext{
32 Sin pretender ahora abordar, ni mucho menos, el problema -que merece mayor consideración-, parece viable sostener que la competencia de los órganos jurisdiccionales contencioso-administrativos se extiende en todo caso, claramente, a las actuaciones incluidas en el procedimiento administrativo general para la iniciación de actividades económicas, así como, por lo menos en los casos de sociedades unipersonales, al resto de decisiones de los órganos de éstas, en la medida en que se trata de decisiones imputables, en definitiva, a la Corporación municipal, la cual adopta mediante sus propios órganos de gobierno (Pleno) aquellas decisiones que luego habrán de expresarse externa y aparentemente como decisiones de los órganos societarios. A nadie se le escapa, desde luego, que la opción por una u otra jurisdicción plantea problemas nada despreciables, como lo es, con carácter previo, la consideración o no de los actos de la sociedad como actos administrativos, e implica igualmente consecuencias muy notables en sede, por ejemplo, de ejecución de sentencias.
} 